University for Business and Technology in Kosovo

UBT Knowledge Center

UBT International Conference

2013 UBT International Conference

Nov 2nd, 12:15 PM - 12:30 PM

\title{
Can credit scoring models prevent default payments in the banking industry in the period of financial crisis?
}

\author{
Violeta Madzova \\ University Goce Delchev, violeta.madzova@ugd.edu.mk \\ University Goce Delchev Ramadani \\ University for Business and Technology, nehat.ramadani@ubt-uni.net
}

Follow this and additional works at: https://knowledgecenter.ubt-uni.net/conference

Part of the Business Commons

\section{Recommended Citation}

Madzova, Violeta and Ramadani, University Goce Delchev, "Can credit scoring models prevent default payments in the banking industry in the period of financial crisis?" (2013). UBT International Conference. 40.

https://knowledgecenter.ubt-uni.net/conference/2013/all-events/40

This Event is brought to you for free and open access by the Publication and Journals at UBT Knowledge Center. It has been accepted for inclusion in UBT International Conference by an authorized administrator of UBT Knowledge Center. For more information, please contact knowledge.center@ubt-uni.net. 


\title{
Can credit scoring models prevent default payments in the banking industry in the period of financial crisis?
}

\author{
Violeta Madzova ${ }^{1}$, Nehat Ramadani ${ }^{2}$ \\ ${ }^{1}$ University Goce Delcev -Faculty of Economics -Stip \\ ${ }^{2}$ University for Bussiness and Technology,MBE \\ Prishtina, Kosova \\ violeta.madzova@ugd.edu.mk ${ }^{1}$,nehat.ramadani@ubt-uni.net ${ }^{2}$
}

\begin{abstract}
Abs tract:Credit scoring is a scientific method of assessing the credit risk associated with new credit applications as well as for monitoring of the credit risk in the process of the loan payment. Therefore credit scoring models developed in the banks based on their internal information system, as well as the credit info system in the country, can help the banks to ensure more consistent underwriting and can provide management with a more insightful measure of credit risk. While credit scoring could be a valuable risk management tool in virtually any bank setting, it is probably not wide accepted in the banks with more fundamental underwriting problems such as inexperienced loan officers, inadequate credit procedures, underdeveloped internal and external credit info - system , persistent arrears problems, etc. However credit scoring is only useful, and can make reliable predictions, if the credit scoring models are properly made, data base updated and credit scoring limitations are properly understood, which is very difficult in the turbulent economic environment as it is the world economy in the recent years. Therefore, the paper objective is to analyze if the banking industry can prevent credit default payments through the implementation of the credit scoring models and what are the parameters and the weights that need to be incorporated, so that the models to be more effective in the period of financial crises.
\end{abstract}

Key words: credit scoring, banks, default payments, credit risk, creditworthiness .

\section{Introduction}

Until recently, the decision to grant credit was bas ed on human judgment to assess the risk of default . However, the growth in the demand for credit, the need for efficient creditworthiness assessment and development of IT techniques, have introduced the use of quantitative and objective methods, generally known as credit scoring, to help credit providers in decision making, whether to grant credit to an applicant or not. This approach, first introduced in the 1940s, has evolved over the years and developed significantly due to the increased competition in the financial industry, advances in computer technology, and the exponential growth of large databases. Today, a wide range of industries take advantage of credit scores to improve fairness, effectiveness and efficiency. Financial companies use credit sco res to predict the risk of delinquencies and losses, which enables them to better allocate costs. Insurance companies use specialized credit scores to make fairer underwriting decisions.

Credit scores also provide benefits at the macroeconomic level by helping small enterprises attain the funds they need and by facilitating the securitization and sale of financial products in the secondary markets, substantially increasing the influx of capital into a country. However credit scoring is only useful, and can make reliable predictions, if the credit scoring models are properly made, data base updated and credit scoring limitations are properly understood, which is very difficult in the turbulent economic environment as it is the world economy in recent years.

Therefore it is very important to understand the nature of credit scoring, as well as the benefits and limitations of the credit scoring models in order to create appropriate tool for default payments predictions. 


\section{What is credit scoring?}

Credit scoring is a statistical method used to predict the probability that a loan applicant or existing borrower will default or become delinquent. The objective of credit scoring is to help credit providers quantify and manage the financial risk involved in providing credit so that they can make better lending decisions quickly and more objectively. The method produces a "score" that a bank can use to rank its loan applicants or borrowers in terms of risk. To build a scoring model, or "scorecard," developers analyze historical data on the performance of previously made loans, to determine which borrower characteristics are useful in predicting, whether the loan performed well. A well-designed modelshould give a higher percentage of high scores to borrowers whose loans will perform well and a higher percentage of low scores to borrowers whose loans won't perform well. As such, scoring models have a wide range of sophistication, from very simple models with only a few data inputs that predict a single outcome to very complex models that have several data inputs and that predict several outcomes. Each bank may use one or more generic, semi-custom, or custom models, any of which may be developed by a scoring company or by internal staff. They may also use different scoring models for different types of credit. Several statistical methods are used to develop credit scoring systems, including Linear probability models, LOGIT models, PROBIT models, and Discriminate analys is models. The first three are standard statistical techniques for estimating the probability of default based on historical data on loan performance and characteristics of the borrower. These techniques differ in that the linear probability model assumes there is a linear relationship between the probability of default and the factors; the Logit model assumes that the probability of default is logistically distributed and the Probit model assumes that the probability of default has a (cumulative) normal distribution. Discriminate analysis differs in that instead of estimating a borrower's probability of default, it divides borrowers into high and low default-risk classes. Two newer methods beginning to be used in estimating default probabilities include options-pricing theory models and neural networks. Options-pricing theory models start with the observation that a borrower's limited liability is comparable to a put option written on the borrower's assets, with strike price equal to the value of the debt outstanding. If, in some future period, the value of the borrower's assets falls below the value of its outstanding debt, the borrower may default. Neural networks are artificial intelligence algorithms that allow for some learning through experience to discern the relationship between borrower characteristics and the probability of default and to determine which characteristics are most important in predicting default. This method is more flexible than the standard statistical techniques, since no assumptions have to be made about the functional form of the relationship between characteristics and default probability or about the distributions of the variables or errors of the model, and correlations among the characteristics are accounted for. In general, neural networks were not clearly better than the standard methods, but suggested using both types of methods in certain applications, especially complex ones in which the flexibility of neural networks would be particularly valuable.

\subsection{The benefits of credit scoring}

Credit scoring offers multiple benefits at every level of the economy:

Credit scores have enabled lenders to extend into historically underserved market se gments. In addition, decisions are faster and more objective with the majority of applicants receiving answers within minutes, rather than days. A study by the Business Banking Board found that the traditional loan approval process averages about 12-1/2 hours per small-business loan, and in the past, lenders have taken up to two weeks to process a loan .

- By using credit scores to predict risk more effectively, lenders have been able to reduce the cost of such vital services as mortgages, personal loans and credit cards.

- Despite this expansion into traditionally underserved markets, moral hazard rates are actually lower with credit scores because lenders can more proactively monitor risk and maintain it at more appropriate levels.

- For consumers, scoring is the key to homeownership and consumer credit. It increases competition among lenders, which drives down prices. Decisions can be made faster and cheaper and more consumers can be approved. It helps spread risk more fairly so vital 
resources, such as insurance and mortgages, are priced more fairly. As such, it greatly reduces the need for human intervention on credit evaluation and the cost of delivering credit

- For businesses, especially small and medium-sized enterprises, credit scoring increases access to financial resources, reduces costs and helps manage risk.

- For the national economy, credit scoring helps smooth consumption during cyclical periods of unemployment and reduces the swings of the business cycle.By enabling loans and credit products to be bundled according to risk and sold as securitized derivatives, credit scoring connects consumers to secondary capital markets and increases the amount of capital that is available to be extended or invested in economic growth. Credit scoring also plays a vital role in economic growth by helping expand access to credit markets, lowering the price of credit and reducing delinquencies and defaults.

- Credit scores also help to reduce discrimination because credit scoring models provide an objective analys is of a consumer's creditworthiness. This objectivity helps lenders ensure they are applying the same underwriting criteria to all borrowers regardless of race, gender, or other factors prohibited by law from being used in credit decisions.

- A credit scoring model makes it easier for a lender to document the business reason for using a factor that might have a disproportionately negative effect on certain groups of applicants protected by law from discrimination. This also enables credit providers to focus on only information that relates to credit risk and avoid the personal subjectivity of a credit analyst or an underwriter .

- Further, credit scores can help financial institutions determine the interest rate that they should charge their consumers and to price portfolios. Higher-risk consumers are charged a higher interest rate and vice versa.

Even if a bank does not want to depend solely on credit scoring for making its credit decisions, scoring can increase efficiency by allowing loan officers to concentrate on the less clear-cut cases.

\subsection{Limitations of credit scoring}

Whether the credit scoring models will be efficient or not in predicting defaults in payments it depends on several aspects that might be considered as credit scoring limitations. If the banking industry intends to predict defaults in payments the following aspects need to be analyzed:

The first group of aspects refers to the quality of the constructed credit scoring model based on the observed data for some certain period of time.

The second group refers to the experience and knowledge and understanding of the banking staff and management related to the work and interpretation of the credit scoring models as well as the credit policy of each bank.

The third group refers to the volatility of economy cycles and the use of the credit scoring models created in the different phase of the economic cycle.

The first group of aspect is referring to the accuracy of the credit scoring models which directly affect their efficiency in predicting defaults in payments. Errors in model construction can lead to inaccurate scoring and consequently to booking riskier accounts than intended and/or to a failure to properly identify and address heightened credit risk within the loan portfolio. Even if the lender can lower its costs of evaluating loan applications by using scoring, if the models are not accurate, these cost savings would be eaten away by poorly performing loans.

There are different reasons for the errors in model construction. Generally, limitations related to credit scoring construction are referring to the fact that the scoring model outputs are only as good as the inputs that are used i.e. if the data are relevant, if the time for observation and testing is enough, if the variables are properly selected and weights properly measured.

One of the major problems that can arise when constructing a credit scoring model is that the model may be built using a biased sample of consumers and customers who have been granted credit. This may occur because applicants (i.e., potential customers) who are rejected will not be included in the 
data for constructing the model. Hence, the sample will be biased (i.e., different from the general population) as good customers are too heavily represented. The credit scoring model built using this sample may not perform well on the entire population since the data used to build the model is different from the data that the model will be applied to. Also, if data going into the scoring model is inaccurate (for instance, if information on the consumer's credit bureau report is erroneous), the model's output (score) will be erroneous. Additional limitation, when constructing credit scoring models is the change of patterns over time. The key assumption for any predictive modeling is that the past can predict the future. In credit scoring, this means that the characteristics of past applicants who are subsequently classified as "good" or "bad" creditors can be used to predict the credit status of new applicants. Sometimes, the tendency for the distribution of the characteristics to change over time is so fast that it requires constant refreshing of the credit scoring model to stay relevant. Depending on how the erroneous information is weighted in the scoring formula, the impact on the score could be substantial. Moreover, if management does not select and properly weight the best predictive variables, the model's output will likely be less effective than had the most predictive variables been used and properly weighted.

The second group of aspects refers to the human capacity of the bank staff and management and their credit policy, especially related to the cut-off level, when the scoring model are used for the credit decision for accepting or rejecting loan applications. Determining whether scoring models are managed by people who understand the credit scoring models, their construction and proper interpretation of their results. Bankers lacking a complete understanding of how the models are made, how they should be used, or how they interface with the bank's lending policies and procedures can expose the bank to risks. In fact credit scores do not generate, accept or reject decisions. It is up to the banking staff to interpret the score results and management to make final decisions about credit approvals or rejections. Even in cases where a banks make their decision solely on a ccustomer's credit score,each bank when deciding about credit approval, still sets its specific score "cut-offs" based on its own business strategies, credit policy considered analys is and prior experience.. Each bank develops its own policies and risk tolerances for its credit card lending programs. Setting cut-off scores is one way banks implement those risk tolerances. A cut-off score is the point below which credit will not be extended and at or above which credit will be extended (assuming a higher score equates to better creditworthiness). A bank might have more than one cut-off score, with each tailored to a specific population. The ability to customize cut-off scores allows management to maximize the approval rate without sacrificing ass et quality. Some banks have cut-off bands, which define a range of scores for which the consumer would undergo additional judgmental review. Selecting a cut-off score involves determining the optimum balance between approval and loss rates. Management evaluates how much additional revenue will be added if the approval rate is increased and what the cost associated with the incremental increase in the bad rate will be. They also often give consideration to marketing expenses and customer service expenses. How management chooses to balance the competing goals determines the cut-off score. Odds charts are often involved in setting cut-off scores and are discussed in the next section. As time passes, cut-off scores and models become less predictive because of economic changes, demographic shifts, and entry into new markets. Examiners should assess management's practices for reviewing cut-off scores and models, including resulting acceptance and loss rates. By monitoring the rates, management can appropriately adjust the cut-off score to change either acceptance rates or loss rates, depending on the strategic goals Some banks and other financial institutions in U.S. through credit scoring created so called "score-polishing phenomenon". Namely, trying to adapt to their customers and using credit scores in theircredit decisions process, they were dedicated in helping their borrowers to improve their credit scores by rearranging finances rather than obeying the simple rule: pay your bills on time and keep your debt low. Such score-polishing actions could potentially distort the patterns of credit default.

The third group of aspects which might reduce effectiveness of the model output (scores) are referring to the factors such as changing economic conditions and business environments through economic cycles of each country and worldwide. Credit scoring is good at predicting the probability of default but generally not at predicting the magnitude of losses. Generic credit scoring models in particular most likely rank order the risk appropriately but generally do not accurately predict the level of the risk. Thus, 
banks that use generic models should not assume that their loss rates will be the same as those reflected in industry odds charts.

Along similar lines, during times of strong economic growth, models may be ill-prepared to predict borrower performance in recessionary conditions, particularly if the historic period observed did not include recessionary conditions. It is important to indentify whether management monitors warning signs of market deterioration, such as increases in personalbankruptcies, which may affect the accuracy of model assumptions.

\section{The effectiveness of credit scoring models in the global financial crisis}

The global financial crisis has dramatically changed the world we live in. Sub-prime mortgages, which arguably initiated the cris is, account for fourteen per cent of the US mortgage market and although this is a relatively high proportion by global standards, the impact of these products on the global financial system shocked experts around the world. . Banking executives throughout the world have realized that a lack of discipline in risk management was a significant factor in the credit crisis. For many, these events have brought into question the credit assessment process, including the role of credit scoring. Sophisticated credit scoring models were pointed out as significant component in any sound credit risk assessment process as well as the key to survival and profitability in this new and constantly changing environment. However, in the turbulent period as the recent financial and economic crises period is , the financial data and their accuracy and consistency become the major problem in construction of reliable credit scoring models. The accuracy of a scorecard is dependent on the quality of the data that is utilized and the matching and weighting of the data elements to an appropriate forecasting horizont. Having in mind that in the crisis period the unemployment is rising, market conditions are deteriorating and consumer spending is declining - all of these trends directly lead into a higher level of corporate delinquencies and consumer defaults. Therefore it is critical that the information utilized in the assessment process is timely enough to predict future behaviors and outcomes. Namely, in a changing or turbulent economic climate, this information on trade payments, recent debt increase among companies and their profitability are vital for establishing a sound and up to date understanding of a companies' financial stability. Since economic environment and conditions are changed it is unavoidably effects the quality of the credit scoring models i.e. the result and the decisions that the banking sector need to make on future corporate lending. The value of application information decreases substantially overtime and in the period of crisis, when the used variables dramatically turn done, there is a lag between a credit event and the credit assessment process, which don't make credit scoring model reliable enough in prediction of credit defaults.

There is also a problem of setting the cut-off level. The decisions that were made with the previously determined credit scoring "cut-off"level might create future defaults and losses for the banks due to the worsened economic conditions. Even the banks with previously more relax credit policy, need to strengthen their credit rules and adjust (increase) the credit scoring "cut-off "level.

Given the extent of the changes that have taken place over the past 3-4 years, the obvious question is will credit scoring models continue to work in the current climate?

From the perspective of ranking potential customers according to the likelihood of default yes, the models will continue to work, however the odds associated with the scores will change. This was confirmed by some recent analysis undertaken by Decision Intellect.

The shifts should not be too drastic but credit providers will need to adjust their cut-off scores in order to prevent substantial increases in bad debt. Maintaining customer acquisition targets and current bad debt levels in the current climate is a difficult task for three key reasons:

1. maintaining current scorecard acceptance levels will result in increased bad debt

2. adjusting the cut-off level will likely result in reduced revenue because a smaller number of applicants will be approved

3. some existing customers that have historically exhibited positive credit behaviours will now default. Consequently organizations need to make a choice between meeting the customer acquisitions targets that have been set and accepting a significant increase in bad debt or downgrading the acquisition targets and minimizing the increase in bad debt write-off. 


\section{How to make credit scoring more effective for default payment prediction?}

It is evident that credit scoring models will continue to be robust enough to risk rank customers. However, if they are not re-visited to account for the impact of current economic conditions on cred it capacity and behaviour, credit providers will experience a significant increase in bad debt. This need to change should not be perceived as a burden, rather it provides an opportunity for organis ations to ensure they have a systemin place which enables them to effectively as sess and manage customers throughout all aspects of the credit lifecycle. Countries that haven't prepared for the changes have experienced some short term negative outcomes such as a rise in defaults and a contraction in lending as the true picture of household debt emerges. However, over time lending returns to normal levels, and indeed exceeds previous levels, but without a subsequent rise in defaults. This means improved access for some sections of the community, particularly SMEs, and lower costs of borrowing..

More precisely, the banks or any other lender using credit scoring need to be aware that:

- Even limited information is of value - the simple inclusion of the existence of accounts allows lenders to acquire a true understanding of a client's debt profile

- The number of data sharers is as important as the data shared - results are best in a system where comprehensive data is shared by a wide variety of credit providers

- Benefits outweigh implementation costs - the benefits that can be realised through improved portfolio performance far outweigh the IT investment required to develop new systems.

Having this knowledge and being prepared to plan and manage the transition process will ensure that the maximum benefits can be obtained for consumers and lenders. New data will impact existing scorecards and credit providers need to prepare for this.

Further, the lifespan of the of a scorecard need to be considered since it depends on a number of factors, including:

- the outcome being modelled;

- major changes within the business; and

- external impacts such as we are currently experiencing.

Since the economic turbulences influence on the credit capacity of the customers, therefore some key trends (that might be put as variables and properly weighted,) need to be considered.

From a commercial perspective, the key trends that will impact credit capacity and performance are: Business failures: the banks in each country need to indentify business es that were under administration or went to bankruptcy over the crisis period

Corporate risk: percentage of the failures were dramatically been increased over the recent severalyears which varies between $20-30 \%$

Cashflow and re-financing issues: Many companies have been relying on cheap funding from banks and they are now faced with an environment in which it is difficult to access cheap credit or in some instances, to access credit at all.

Slowing payment terms: for example, businesses in U.S. in 2009/10 were averaging 56.5 days to settle accounts, the highest level since 2001

From a consumer perspective the key influences on credit performance are:

Unemployment: depending on each country but dramatically increase of unemployment averages from $10-12 \%$

Personal insolvencies: The number of personal insolvencies increased by twelve per cent year-on-year in U.S. in the period 2008-2010.

Declining household wealth: In many instances this related to depreciating ass et values, and the prices of mortgages which drastically went down in 2008-2009, haven't recovered since today.

Savings and debt: due to the decrease of income and high rate of unemployment, there are less income to be saved, so the saving rate also varies from country to country are general are lower and there is general higher debt to income rate. 


\section{Recommendations for accuracy improvement of the credit scoring models}

The accuracy of a credit scoring system will depend on the care with which it is developed. The sample selected to build the model is one of the most important aspects of the developmental effort. A large enough sample is needed to make the model statistically valid. The sample must also be characteristic of the population to which the scorecard will be applied. Because of the significant variance in characteristics between subprime and prime populations, banks offering subprime products should not rely on models developed solely for products offered to prime borrowers .

The data on which the system is based need to be a rich sample of both well-performing and poorly performing loans. The data should be up to date, and the models should be re estimated frequently to ensure that changes in the relationships between potential factors and loan performance are captured.

The use of credit scoring itself may change a bank's applicant pool in unpredictable ways, since it changes the cost of lending to certain types of borrowers.

Again, this change in applicant pool may hurt the accuracy of a model that was built using information from the past pool of applicants. Account should be taken not only of the characteristics of borrowers who were granted credit but also of those who were denied.

A model's accuracy should be tested. A good model needs to make accurate predictions in good economic times and bad, so the data on which the model is based should cover both expansions and recessions .And the testing should be done using loan samples that were not used to develop the model in the first place. It's important to remember, though, that a credit scoring model is not going to tell a lender with certainty what the future performance of an individual loan will be. When loan approval decisions are based solely on credit scores, some borrowers will be granted credit but will ultimately default, which visibly hurts the lender's bottom line. Other borrowers won't be granted credit even though they would have repaid, which, though less visible, also hurts the lender's profitability.

No scoring model can prevent these types of errors, but a good model should be able to accurately predict the average performance of loans made to groups of individuals who share similar values of the factors identified as being relevant to credit quality.

Therefore, management must make sure that the variables used in the models are appropriate, predictive, and properly weighted to arrive at the best credit decision and that data inputs are complete and accurate

\section{Conclusions}

Credit scoring models can lead to improved credit scoring results. More generally, from a management perspective, it is worthwhile noting that credit scoring has the following benefits: (1) reduced subjectivity and increased objectivity in risk assessment, (2) increased speed and consistency of risk ass essment, (3) possible automation of the risk as essment process, (4) reduced cost of risk assessment, (5) better allocation of resources, (6) better determination of interest rate, loan duration, loan amount, etc., (7) better risk management, (8) better collection/recovery strategies, and (9) possible development of non-traditional markets. However, even a good scoring system won't predict with certainty any individual loan's performance, but it should give a fairly accurate prediction of the likelihood that a loan applicant with certain characteristics will default. To build a good scoring model, developers need sufficient historical data, which reflect loan performance in periods of both good and bad economic conditions. Despite the limitations highlighted above, there is no doubt that credit scoring will continue to be a major tool in predicting credit risk in consumer lending. It is envisaged that organizations using credit scoring appropriately will gain important strategic advantage and competitive edge over their competitors.

\section{References}


1. Koh H.C; Tan W.C; Goh C. P., " Two-step Method to Construct Credit Scoring Models with Data Mining Techniques International Journal of Business and Information, Volume 1 Number 1, 2006 pp 96-118;

2. Wantland, R. "Best Practices in Small Business Lending for Any Delivery System," Journal of Lending and Credit Risk Management (December 1996), p. 16-25.;

3. Vallini C.,Ciampi F., Gordini N.,'Can Credit Scoring Models Effectively Predict Small Enterprise Default? " 8th Global Conference on Business \& Economics October 18-19th, 2008, Florence, Italy.;

4. Whitepaper, 2009. "The implications of the global credit crisis for credit scoring models" Dun\&Brads Street Company -Decision Intellect.;

5. TransUnion Whitepaper 2007 "The Importance of Credit Scoring for Economic Growth" Trans Union ,555 West Adams,Chicago, Illinois,.;

6. Lahsasna A., .Ainon, R, Wah T.Y; "Credit Scoring Models Using Soft Computing Methods: A Survey" The International Arab Journal of Information Technology, Vol. 7, No. 2, April 2010 . 